\title{
Colégio Pedro II: Um estudo sobre legislação e indicadores aplicados
}

\author{
Colégio Pedro II: A study on legislation and applied indicators \\ Colégio Pedro II: un estudio sobre legislación e indicadores aplicados
}

Recebido: 22/02/2021 | Revisado: 26/02/2021 | Aceito: 27/02/2021 | Publicado: 02/03/2021

\author{
Ricardo Dias das Neves \\ ORCID: https://orcid.org/0000-0003-2503-5560 \\ Colégio Pedro II, Brasil \\ E-mail: rdneves1@yahoo.com \\ Adjovanes Thadeu Silva de Almeida \\ ORCID: https://orcid.org/0000-0002-1618-4153 \\ Colégio Pedro II, Brasil \\ E-mail: adjovanes@cp2.g12.br
}

\begin{abstract}
Resumo
Criado no ano de 1837, o Colégio Pedro II tem sua área de atuação desde a Educação Infantil até a Pós-Graduação Stricto Senso. A Lei 11.892 de 2008 criou os Institutos Federais e teve sua redação atualizada pela Lei 12.677 de 2012, incluindo o Colégio Pedro II na Rede Federal de Educação, Científica, Profissional e Tecnológica. A Lei 12.677/12 manteve a tradicional denominação de "Colégio Pedro II", equiparando-o, contudo, à condição de Instituto Federal de Educação, Ciência e Tecnologia. O artigo, aborda, principalmente, os aspectos legais desta equiparação, explicando conceitos jurídicos e comentando os principais artigos da legislação pertinente, além de analisar relevantes indicadores econômicos e sociais da instituição.
\end{abstract}

Palavras-chave: Educação Profissional; Instituto Federal; Legislação; Indicadores.

\begin{abstract}
Created in 1837, Colégio Pedro II has its area of activity from Early Childhood Education to the Stricto Senso Graduate Program. Law 11,892 of 2008 created the Federal Institutes and had its wording updated by Law 12,677 of 2012, including Colégio Pedro II in the Federal Education, Scientific, Professional and Technological Network. Law 12.677/12 maintained the traditional name "Colégio Pedro II", however, equating it to the condition of Federal Institute of Education, Science and Technology. The article mainly addresses the legal aspects of this assimilation, explaining legal concepts and commenting on the main articles of the relevant legislation, in addition to analyzing relevant economic and social indicators of the institution.
\end{abstract}

Keywords: Professional Education; Federal Institute; Legislation; Indicators.

\section{Resumen}

Creado en 1837, el Colégio Pedro II tiene su área de actividad desde Educación Infantil hasta el Programa de Posgrado Stricto Senso. La Ley 11.892 de 2008 creó los Institutos Federales y tuvo su redacción actualizada por la Ley 12.677 de 2012, incluyendo al Colégio Pedro II en la Red Federal Educativa, Científica, Profesional y Tecnológica. La Ley 12.677/12 mantuvo el nombre tradicional de "Colégio Pedro II", sin embargo, equiparándolo a la condición de Instituto Federal de Educación, Ciencia y Tecnología. El artículo aborda principalmente los aspectos legales de esta asimilación, explicando conceptos legales y comentando los principales artículos de la legislación pertinente, además de analizar indicadores económicos y sociales relevantes de la institución.

Palabras clave: Educación profesional; Instituto Federal; Legislación; Indicadores.

\section{Introdução}

Este artigo apresenta, como tema, os aspectos legais correlacionados ao Colégio Pedro II, no contexto da educação profissional e tecnológica. Aborda, a Lei n ${ }^{\circ} .11 .892$ de 2008, que criou os Institutos Federais de Educação, Ciência e Tecnologia e a Lei n ${ }^{\circ} 12.677$ de 2012, responsável pelo enquadramento do Colégio Pedro II como Instituto Federal. Também, são analisados importantes indicadores econômicos e sociais, abrangendo aspectos das políticas públicas vigentes.

A Constituição Federal de 1988, em seu artigo 205, dispõe sobre o tema Educação: "direito de todos e dever do Estado e da família, a ser promovida e incentivada com colaboração da sociedade, visando ao pleno desenvolvimento da pessoa, seu 
preparo para exercício da cidadania e sua qualificação para o trabalho" (Brasil, CF, 1988, art. 205). A Educação é, portanto, reconhecida pelo Estado como direito indispensável à dignidade da pessoa humana.

No que se refere ao ensino público, em seu artigo 208, a Constituição Federal assegura, além da gratuidade, outros direitos: "progressiva universalização do ensino médio gratuito" e "acesso aos níveis mais elevados do ensino, da pesquisa e da criação artística" (Brasil, CF, 1988, art. 208).

O presente artigo adota como base os Princípios, Objetivos e Finalidades da EPT (Educação Profissional e Tecnológica), segundo Marise Ramos (2005, p. 5).

A politecnia não significa o que se poderia sugerir a sua etimologia, a saber, o ensino de muitas técnicas. Politecnia significa uma educação que possibilita a compreensão dos princípios científico-tecnológicos e históricos da produção moderna, de modo a orientar os estudantes à realização de múltiplas escolhas (Ramos, 2005, p.5).

A politecnia pressupõe o conhecimento intelectual, e sobretudo, a formação humana, possibilitando o desenvolvimento integral do aluno. Não se refere ao processo de adestramento de um trabalhador para executar determinada tarefa. Diversamente, refere-se a muitos aspectos da produção, já que o trabalhador passa a dominar os princípios da organização moderna e a correlação entre o trabalho manual e o intelectual.

Formar profissionalmente não é preparar exclusivamente para o exercício do trabalho, mas é proporcionar a compreensão das dinâmicas sócio-produtivas das sociedades modernas. (Ramos, 2005, p.10).

No desenvolvimento deste artigo foram utilizadas as pesquisas de natureza qualitativa e quantitativa, com metodologia de pesquisa documental. A pesquisa documental foi realizada a partir da análise detalhada de estatutos, projetos de lei, exposição de motivos, tramitação legislativa, pareceres, regimentos e leis referentes aos Institutos Federais e ao Colégio Pedro II, consultados através dos sites destes órgãos, bem como da legislação correlata ao tema. Na pesquisa quantitativa foram analisados gráficos e tabelas numéricas.

Segundo Pádua (1997, p.62), "Pesquisa documental é aquela realizada a partir de documentos, contemporâneos ou retrospectivos, considerados cientificamente autênticos (não fraudados); a fim de descrever/comparar fatos sociais, estabelecendo suas características ou tendências."

De acordo com Pereira (2018, p.69), "Nos métodos quantitativos, faz-se a coleta de dados quantitativos ou numéricos por meio do uso de medições de grandezas e obtém-se por meio da metrologia, números com suas respectivas unidades. Estes dados podem ser analisados por meio de técnicas matemáticas como é o caso das porcentagens, estatísticas e probabilidades.”

\section{Legislação aplicada ao Colégio Pedro II}

A Constituição Federal de 1988, em seu artigo 205, dispõe sobre o tema Educação: “direito de todos e dever do Estado e da família, a ser promovida e incentivada com colaboração da sociedade, visando ao pleno desenvolvimento da pessoa, seu preparo para exercício da cidadania e sua qualificação para o trabalho" (Brasil, CF, 1988, art. 205). A Educação é, portanto, reconhecida pelo Estado como direito indispensável à dignidade da pessoa humana.

O Colégio Pedro II é citado na Constituição Federal, no artigo 242, § 2으:

$\S 2^{\circ}$ O Colégio Pedro II, localizado na cidade do Rio de Janeiro, será mantido na órbita federal (Brasil, CF, 1988, art. $242, \S 2 \underline{0})$. 
A Lei de Diretrizes e Bases da Educação Nacional, publicada no ano de 1996 (Brasil, 1996) e o Decreto 5.154 de 2004 (Brasil, 2004), foram fundamentais para a construção do arcabouço legal referente à Educação Profissional no Brasil, servindo de base para as leis editadas posteriormente.

A Lei nº 11.892 de 2008 criou os Institutos Federais de Educação, Ciência e Tecnologia, originados da transformação de Centros Federais de Educação Tecnológica, Escolas Agrotécnicas Federais e Escolas Técnicas vinculadas às Universidades Federais.

A partir do Decreto n. 5.154/2004, dispositivo legal cuja formulação se baseou no reconhecimento das necessidades dos trabalhadores, tivemos formas possíveis de se tentar desenvolver a educação integrada, com o objetivo de possibilitar que os sujeitos tenham uma formação que, conquanto garanta o direito à educação básica também possibilite a formação para o exercício profissional. Este sentido equivale à indissociabilidade entre educação profissional e educação básica. Foram regulamentadas formas por meio das quais os sistemas educacionais e as escolas podem buscar a realização de uma formação integrada. Formas essas que se definem como integrada, concomitante e subsequente (Ramos, 2005, p.16).

No conjunto da legislação anterior ao decreto 5.154/2004, a definição explícita dos conceitos de formação integrada, concomitante e subsequente, estava ausente dos textos legais. Este decreto representou um avanço normativo, sobretudo quando comparado com as legislações anteriores.

Pensemos, por exemplo, no âmbito da Física, sobre se o conceito de eletricidade é um conhecimento geral ou específico. Afinal, o desenvolvimento desse conceito não possibilitou termos a luz elétrica iluminando artificialmente uma sala, um dispositivo eletrônico para transmitirmos imagens, um microfone que possibilita a ampliação de nossas vozes? Tais ponderações demonstram que a tecnologia é uma extensão das capacidades humanas (Ramos, 2005, p.16).

A tecnologia atual possibilitou o surgimento do ensino à distância (EAD). Devido à pandemia no ano de 2020, esta modalidade de ensino foi utilizada com sucesso durante as aulas do Mestrado ProfEPT, por meio de aplicativos voltados para reuniões online. Esta tecnologia possibilitou o prosseguimento dos estudos no Mestrado ProfEPT, além da realização de exames de qualificação e defesas de dissertação, todos no formato à distância.

Explicitar teorias e conceitos fundamentais para a compreensão do(s) objeto(s) estudado(s) nas múltiplas perspectivas em que foi problematizada e localizá-los nos respectivos campos da ciência (áreas do conhecimento, disciplinas científicas e/ou profissionais), identificando suas relações com outros conceitos do mesmo campo (disciplinaridade) e de campos distintos do saber (interdisciplinaridade). Por exemplo, a construção de uma usina hidrelétrica numa determinada região, problematizada na perspectiva tecnológica evidenciaria teorias, conceitos e procedimentos técnicocientíficos predominantemente da Física. Mas, se problematizado na perspectiva ambiental, por exemplo, evidenciarse-iam questões, teorias e conceitos da Biologia e da Geografia. Mas toda questão ambiental é também econômica e política, portanto, ao ser tratada nessas perspectivas, serão evidenciados conceitos das Ciências Sociais. Enfim, nenhuma perspectiva em si esgotaria a totalidade do fenômeno. Por isto, o currículo integrado requer a problematização dos fenômenos em múltiplas perspectivas, mas também uma abordagem metodológica que permita apreender suas determinações fundamentais (Ramos, 2005, p.24).

Este é um claro exemplo do conceito de interdisciplinaridade. À primeira vista, as disciplinas envolvidas no projeto e na execução de um empreendimento de grande porte envolveriam apenas algumas especialidades da área de Engenharia, como Civil, Elétrica e Mecânica. Contudo, observamos também o envolvimento de outras Ciências não menos importantes, como a Biologia, a Geografia, e as Ciências Sociais.

A Lei 11.892 de 2008 criou os Institutos Federais de Educação, Ciência e Tecnologia. Como resultado, foram criados 38 institutos, abrangendo o ensino técnico de nível médio, os cursos superiores de tecnologia, licenciaturas, bacharelados 
tecnológicos e engenharias, com a possibilidade de oferecer especializações, mestrados e doutorados nas modalidades profissionais e acadêmicas.

Esta lei foi alterada pela Lei 12.677 de 2012, no qual em seu inciso V, do Art. $1^{\text {o }}$, foi incluído o Colégio Pedro II na Rede Federal de Educação, Científica, Profissional e Tecnológica.

Art. $1^{\circ}$ Fica instituída, no âmbito do sistema federal de ensino, a Rede Federal de Educação Profissional, Científica e Tecnológica, vinculada ao Ministério da Educação e constituída pelas seguintes instituições:

V - Colégio Pedro II. (Incluído pela Lei nº 12.677, de 2012) (Brasil, 2012).

De acordo com o parágrafo único do Art. $4^{\circ}$-A e do Art. 13-A da Lei 12.677 de 2012, o Colégio Pedro II foi equiparado à condição de Instituto Federal:

Parágrafo único. O Colégio Pedro II é equiparado aos institutos federais para efeito de incidência das disposições que regem a autonomia e a utilização dos instrumentos de gestão do quadro de pessoal e de ações de regulação, avaliação e supervisão das instituições e dos cursos de educação profissional e superior.

Art. 13-A. O Colégio Pedro II terá a mesma estrutura e organização dos Institutos Federais de Educação, Ciência e Tecnologia (Brasil, 2012).

Segundo Hely Lopes Meirelles (2013, p.111), a autonomia administrativa significa "o poder de organizar seus próprios serviços, fazê-lo funcionar, inclusive convocar, nos termos da lei, pessoal habilitado". O conceito de autonomia não se confunde com o de soberania. Este é um dos principais fundamentos do Estado Moderno.

Na condição de autarquia, o Colégio Pedro II não possui a competência de produzir as próprias leis, mas somente a capacidade de autoadministrar-se com relação a matérias privativas. Como exemplo do alcance da autonomia, temos a prerrogativa para criar e extinguir cursos e a emissão de diplomas. Para o Colégio Pedro II, a elaboração de proposta orçamentária anual contempla cada campus.

O Colégio Pedro II, reconhecido pela sua importância histórica e por sua tradição na área de Educação, recebeu tratamento diferenciado quando da equiparação à condição de Instituto Federal. No novo arranjo da Rede Federal de Educação, alguns Colégios Técnicos foram enquadrados como campus de Institutos Federais:

1. O Colégio Técnico Universitário (UFJF) tornou-se campus do Instituto Federal do Sudeste de Minas Gerais;

2. O Colégio Agrícola Nilo Peçanha (UFF) tornou-se campus do Instituto Federal do Rio de Janeiro;

3. O Colégio Técnico Industrial Prof. Mário Alquati (FURG) tornou-se campus do Instituto Federal do Rio Grande do Sul;

Segundo Pacheco (2015, p.16),

Os Centros Federais de Educação Tecnológica (CEFETs), as escolas agrotécnicas federais e as escolas técnicas vinculadas às universidades que aceitaram o desafio, desaparecem enquanto tais, para se transformarem nos campi espalhados por todo o país, fiadores de um ensino público, gratuito, democrático e de excelência. Com os Institutos Federais, iniciamos uma nova fase, abandonando o hábito de reproduzir modelos externos e ousando inovar a partir de nossas próprias características, experiências e necessidades (Pacheco, 2015, p.16)

No caso concreto, o Colégio Pedro II não "desapareceu” como instituição, ao contrário, manteve sua denominação secular e foi além, sendo equiparado à condição de Instituto Federal.

A redação do art. $7^{\circ}$, inciso VI, alínea e, da Lei 11.892 de 2008, possibilitou ao Colégio Pedro II ministrar o curso de Mestrado ProfEPT, assim como o Programa de Mestrado Profissional em Práticas de Ensino na Educação Básica (MPPEB), iniciado no ano de 2013: 
VI - ministrar em nível de educação superior:

e) cursos de pós-graduação stricto sensu de mestrado e doutorado, que contribuam para promover o estabelecimento de bases sólidas em educação, ciência e tecnologia, com vistas no processo de geração e inovação tecnológica (Brasil, 2008).

\section{Indicadores do Colégio Pedro II}

Esta seção foi escrita objetivando elucidar questões pertinentes ao Colégio Pedro II, levantadas durante as aulas do curso de Mestrado, tais como, variação de gastos da instituição, perfil sócio-econômico dos alunos e taxa de evasão. Os dados são oriundos da Plataforma Nilo Peçanha (PNP, 2020), coletados no ano de 2019.

No que se refere à classificação racial, aproximadamente 39\% dos alunos declararam-se brancos e 49\%, pardos (Figura 1). Estes percentuais, quando comparados, vão ao encontro dos dados fornecidos pela PNAD do IBGE. As raças classificadas como preta, indígena e amarela apresentam números semelhantes, quando comparadas com os dados fornecidos pelo IBGE.

Figura 1. Classificação Racial e Renda Familiar dos Estudantes do Colégio Pedro II.

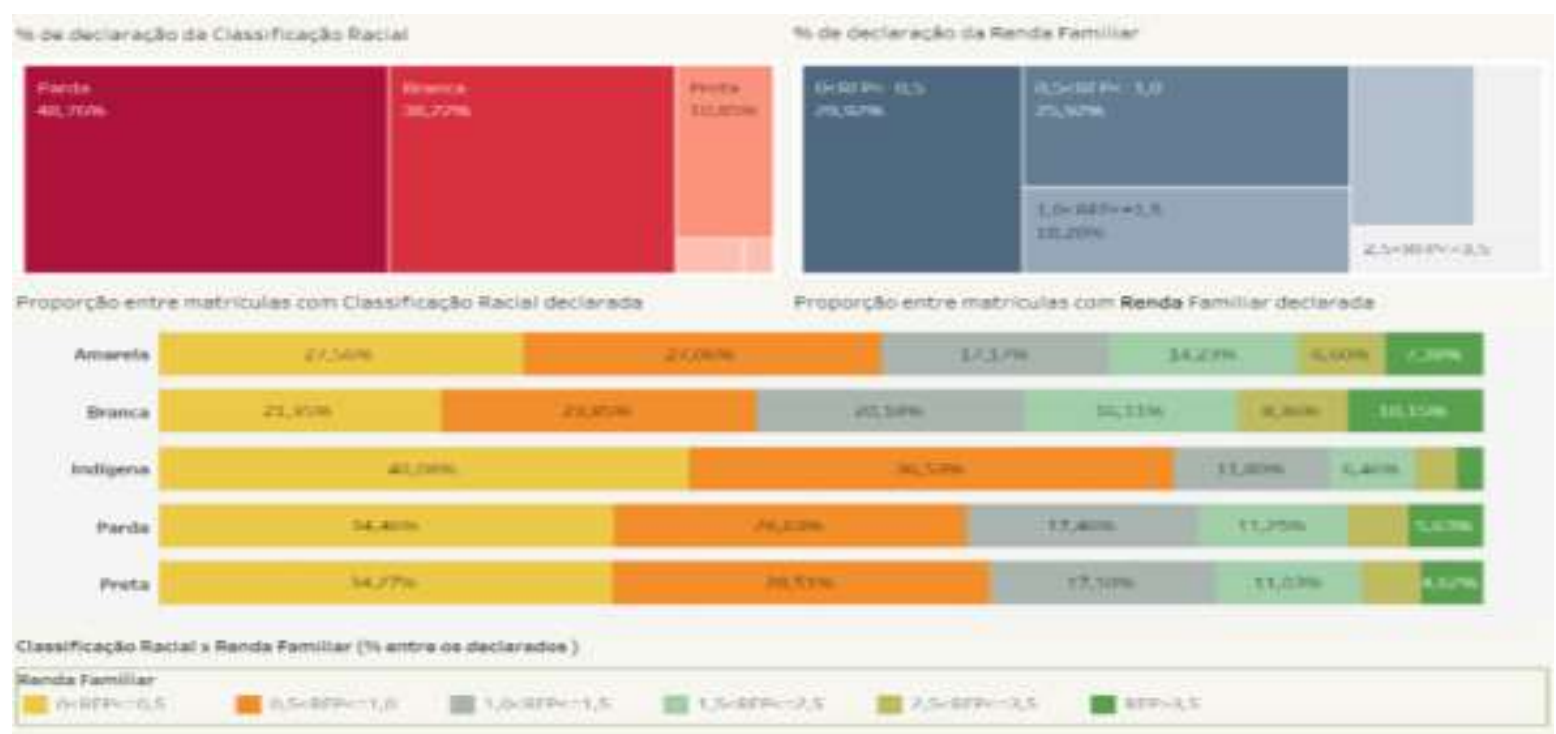

Fonte: http://plataformanilopecanha.mec.gov.br/2020.html

Segundo os dados da PNAD do IBGE, no Brasil, a partir do ano de 2015, aqueles que se auto declararam pardos, passam a representar a maioria da população brasileira (Figura 2).

Figura 2. Classificação Racial do Brasil.

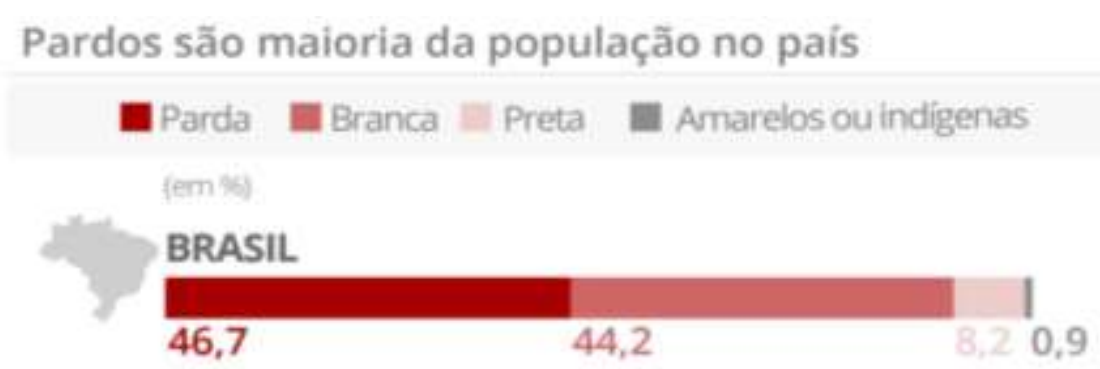

Fonte: https:/g1.globo.com/economia/noticia/populacao-que-se-declara-preta-cresce-149-no-brasil-em-4-anos-aponta-ibge.ghtml. 
Quanto à renda familiar dos estudantes do Colégio Pedro II, apenas 7\% possuem RFP (renda familiar per capta) acima de 3,5 salários-mínimos, reafirmando a importância das políticas de assistência estudantis. A política de cotas foi implantada no Colégio Pedro II no ano de 2004, com 50\% das vagas reservadas para estudantes oriundos de escolas públicas. Por força de lei federal, no ano de 2012, o modelo foi aperfeiçoado, atribuindo $20 \%$ da reserva de $50 \%$ das vagas, para estudantes negros. A política de cotas contribuiu para o ingresso de alunos de classes populares, afastando a hipótese de que a maior parte dos alunos seriam oriundos da chamada "elite".

Entre os anos de 2018 e 2019, houve aumento de 6\% nos gastos do Colégio Pedro II (Figuras 3 e 4). Os gastos com pessoal representaram, no ano de $2019,92 \%$ do gasto total.

Figura 3. Gastos do Colégio Pedro II (2019).

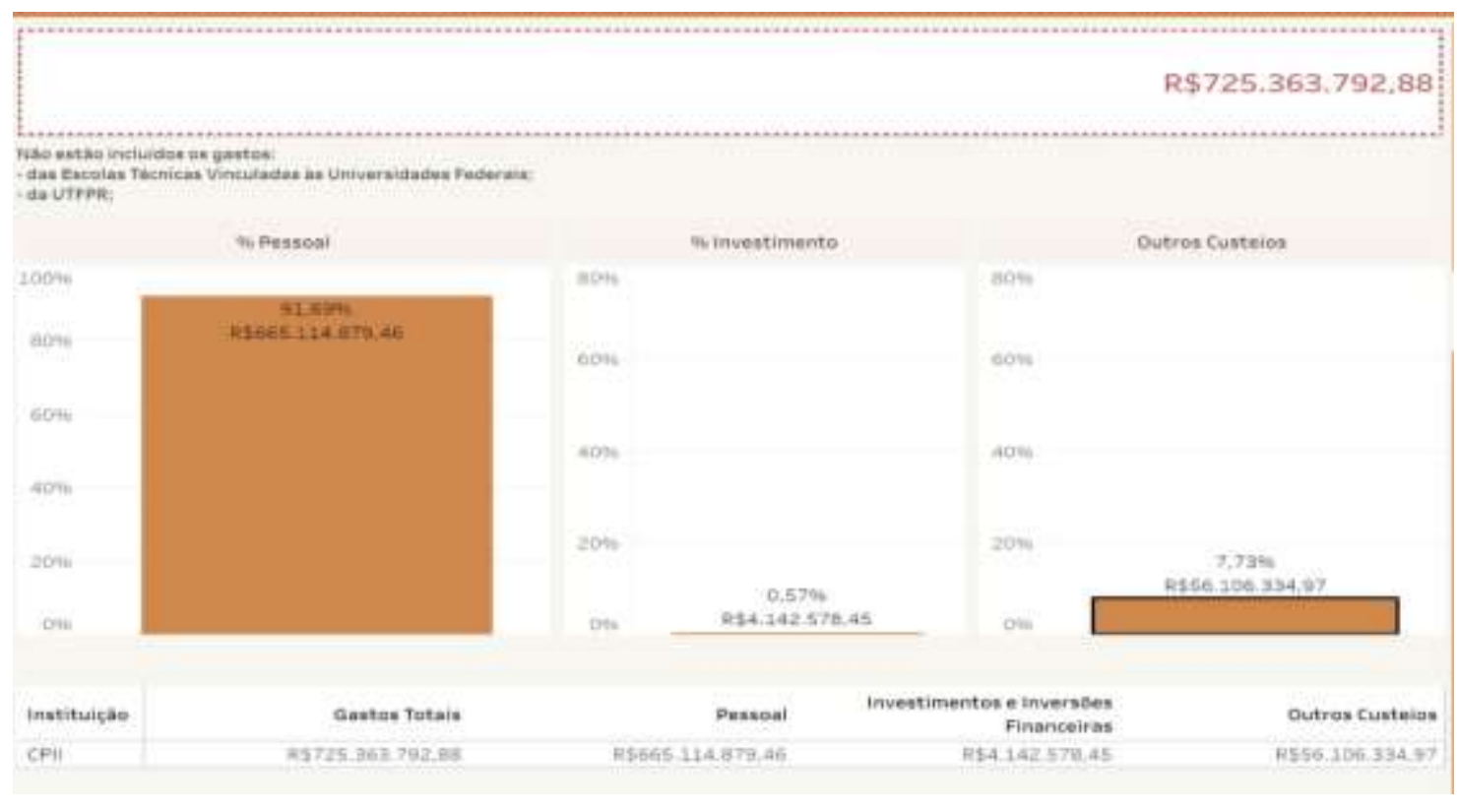

Fonte: http://plataformanilopecanha.mec.gov.br/2020.html

Figura 4. Gastos do Colégio Pedro II (2018).

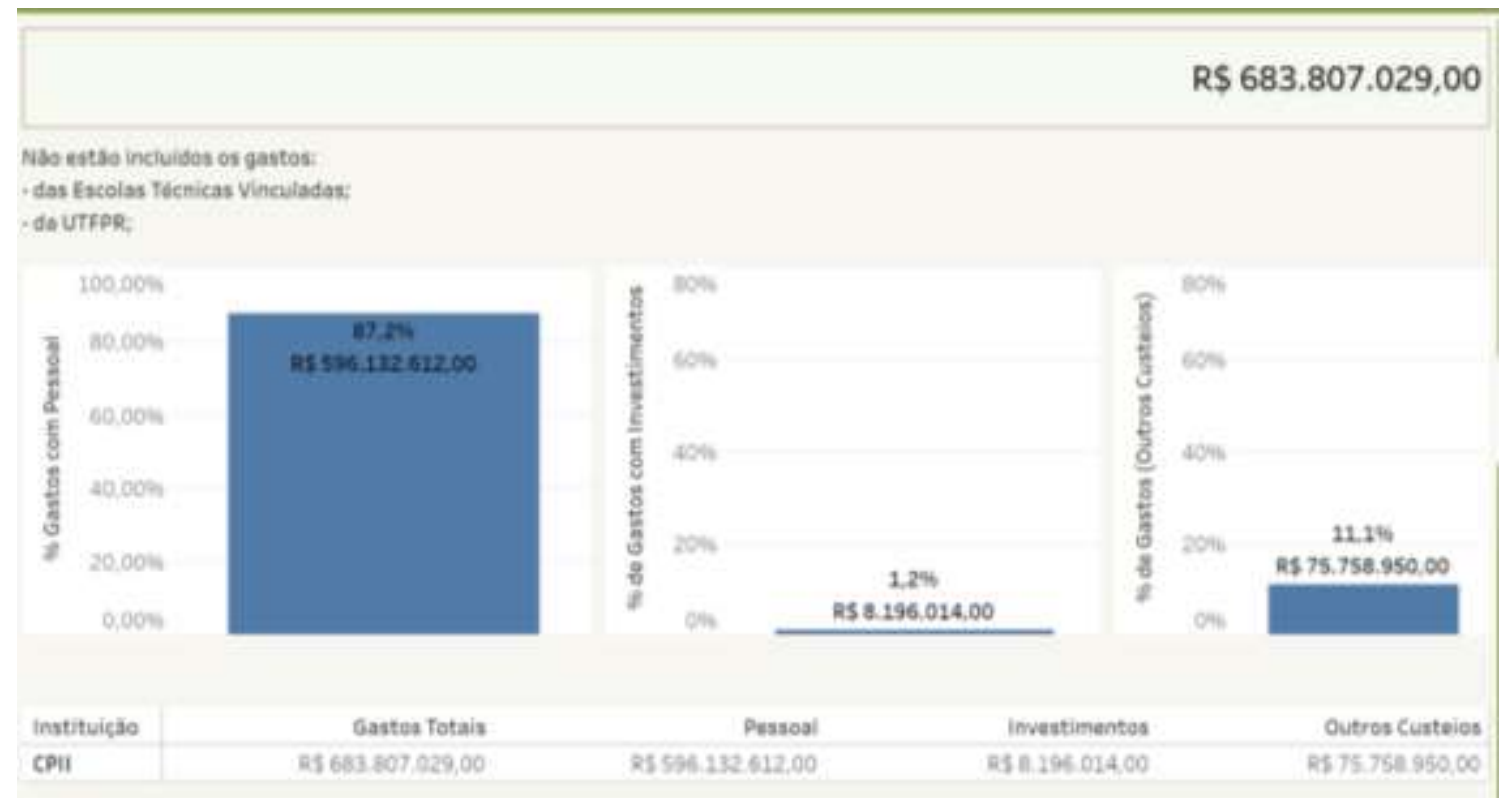

Fonte: http://plataformanilopecanha.mec.gov.br/2020.html 
Quanto ao indicador taxa de evasão, segundo a PNAD Educação do IBGE:

A pesquisa está divulgando pela primeira vez dados sobre abandono escolar. Das 50 milhões de pessoas de 14 a 29 anos do país, 20,2\% (ou 10,1 milhões) não completaram alguma das etapas da educação básica, seja por terem abandonado a escola, seja por nunca a terem frequentado. Desse total, $71,7 \%$ eram pretos ou pardos.

Os resultados mostraram ainda que a passagem do ensino fundamental para o médio acentua o abandono escolar, uma vez que aos 15 anos o percentual de jovens quase dobra em relação à faixa etária anterior, passando de $8,1 \%$, aos 14 anos, para 14,1\%, aos 15 anos. Os maiores percentuais, porém, se deram a partir dos 16 anos, chegando a 18,0\% aos 19 anos ou mais.

Entre os principais motivos para a evasão escolar, os mais apontados foram a necessidade de trabalhar $(39,1 \%)$ e a falta de interesse $(29,2 \%)$. Entre as mulheres, destaca-se ainda gravidez $(23,8 \%)$ e afazeres domésticos $(11,5 \%)$ (IBGE, PNAD, 2019).

O Colégio Pedro II, quando comparado aos demais Institutos Federais, apresenta taxas de evasão em patamares aproximadamente $60 \%$ menores (Figura 5). A taxa de evasão média do Colégio Pedro II possui valor apurado de 6,2\%, contra $15,5 \%$ dos Institutos Federais.

Podemos inferir que a elevada participação do ensino propedêutico no Colégio Pedro II (74\%), aliada ao baixo percentual de evasão neste segmento $(2,4 \%)$, contribuem para o baixo percentual geral de evasão $(6,2 \%)$, na comparação com os demais Institutos Federais.

Figura 5. Taxa de evasão do Colégio Pedro II (2019).

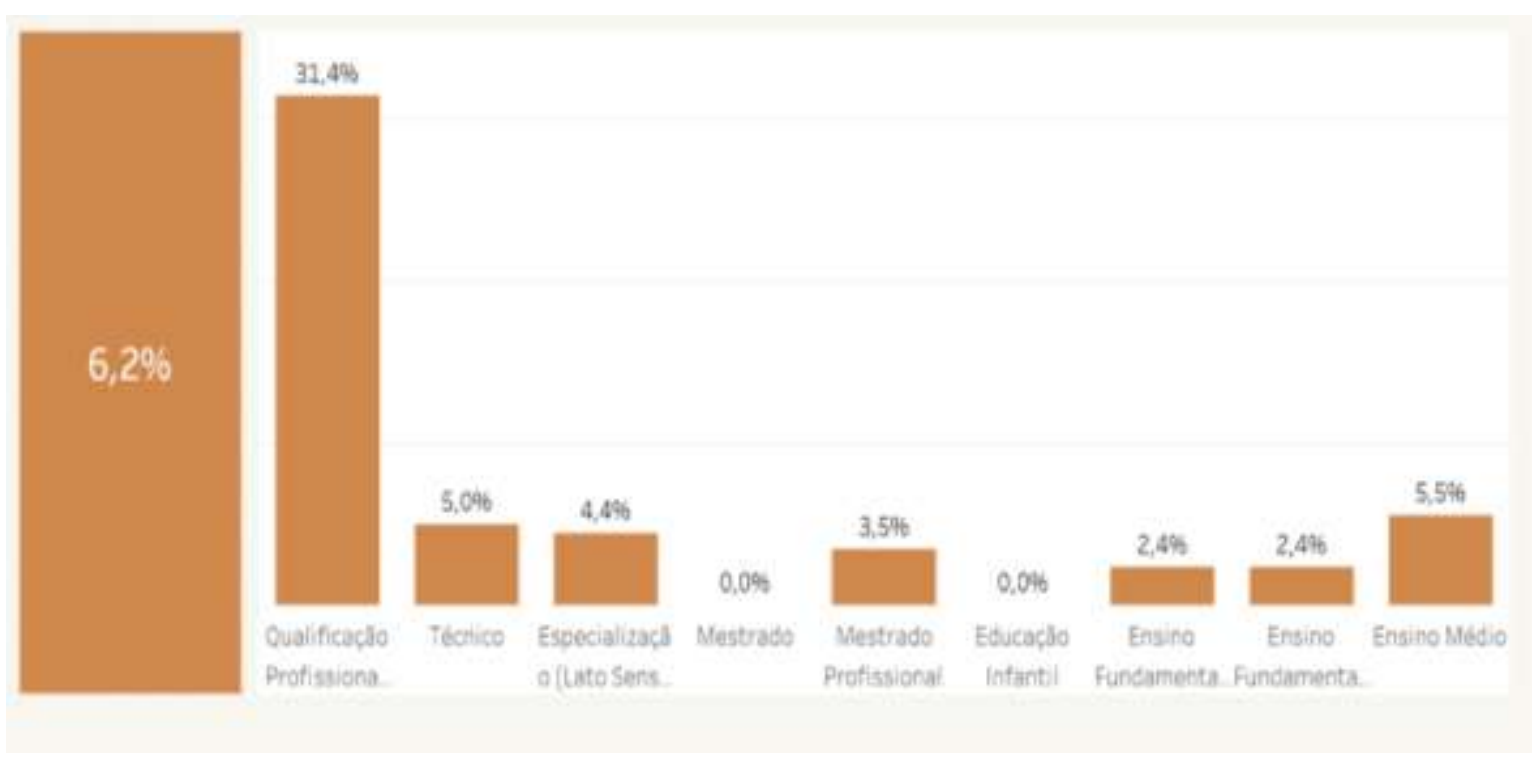

Fonte: http://plataformanilopecanha.mec.gov.br/2020.html

Para o ensino técnico, o valor apurado para o Colégio Pedro II é de 5,0\%, contra $13 \%$ dos Institutos Federias (Figura 6). Segundo a PNAD do IBGE, a taxa de evasão aos 15 anos de idade atinge $14.1 \%$, crescendo até o valor de $18 \%$, aos 19 anos. 
Figura 6. Taxa de Evasão nos Institutos Federais (2019)

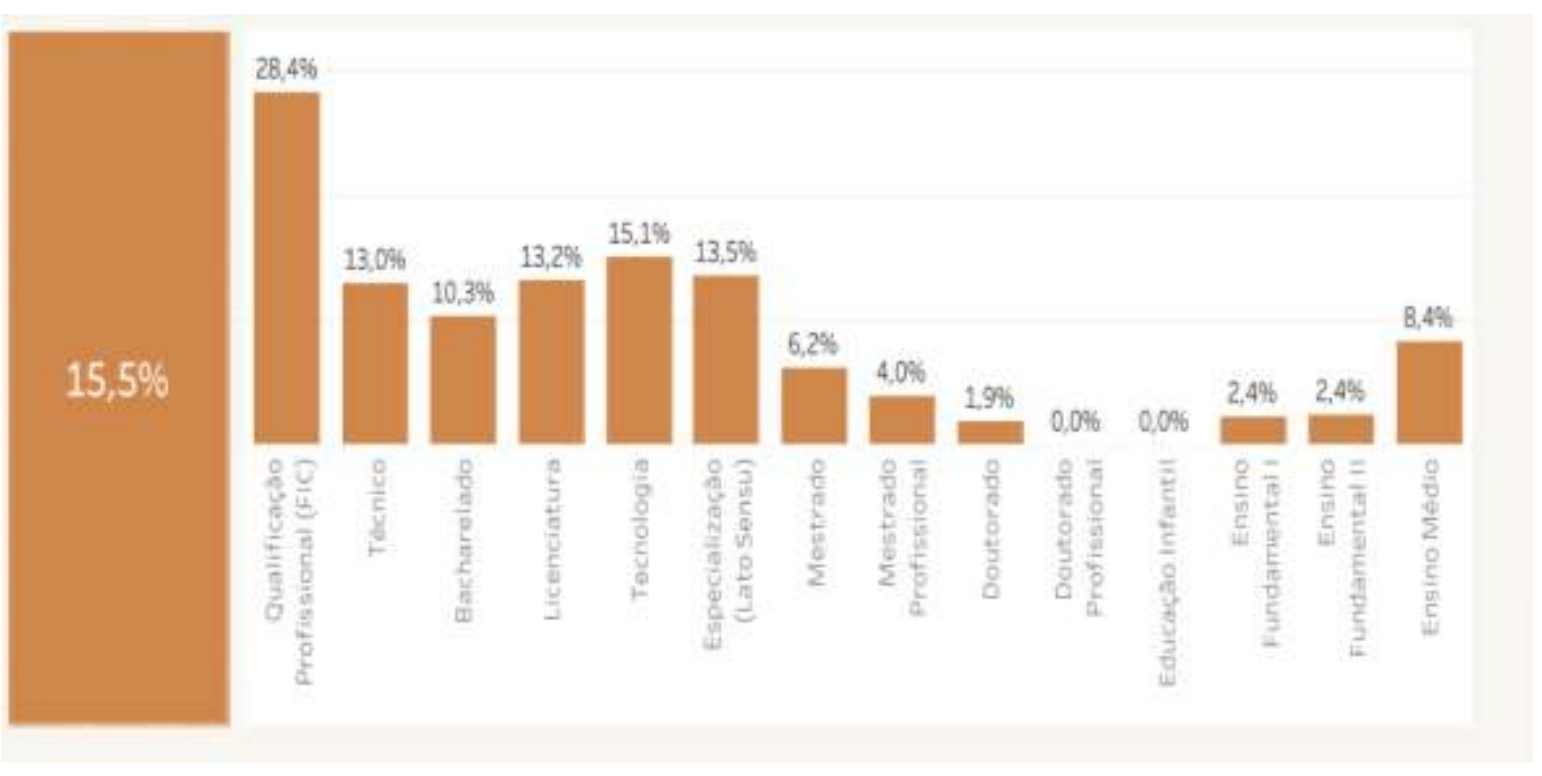

Fonte: http://plataformanilopecanha.mec.gov.br/2020.html

\section{Considerações Finais}

O Colégio Pedro II é uma instituição tradicional e centenária, que compõe a Rede Federal de Educação Profissional, Científica e Tecnológica. Sua missão institucional é: "Promover a educação de excelência, pública, gratuita e laica, por meio da indissociabilidade do ensino, da pesquisa e da extensão, formando pessoas capazes de intervir de forma responsável na sociedade" (CP2, 2019).

O tema desenvolvido vai ao encontro do Planejamento Estratégico do Colégio Pedro II (2019-2023), na dimensão acadêmica e pedagógica: "Disseminar a história do Colégio Pedro II de maneira a preservar a memória institucional e fortalecer os sentimentos de identidade, pertencimento e cidadania" (CP2, 2019).

Este artigo não pretendeu esgotar as interpretações dos assuntos nele abordados, contribuindo, contudo, para a edificação de um conjunto de saberes no âmbito do Programa de Mestrado ProfEPT. As análises sobre indicadores, por exemplo, podem ser aprofundadas em um artigo futuro, direcionado ao tema "Políticas Públicas aplicadas no Colégio Pedro II".

\section{Referências}

Brasil. (2021). Constituição da República Federativa do Brasil. <http://www.planalto.gov.br/ccivil_03/constituicao/constituicaocompilado.htm>.

Brasil. (2021). Decreto $n^{\circ} 5.154$, de 23 de julho de 2004. Regulamenta o $\S 2^{\circ}$ do art. 36 e os arts. 39 a 42 da Lei ${ }^{\circ} 9.394$, de 20 de dezembro de 1996 , que estabelece as diretrizes e bases da educação nacional. < http://www.planalto.gov.br/ccivil_03/_ato2004-2006/2004/decreto/d5154.htm.>.

Brasil. (2021). Lei nº 9.394, 20 de dezembro de 1996. Lei de diretrizes e bases da educação nacional. <http://www.planalto.gov.br/ccivil_03/leis/19394.htm>.

Brasil. (2021). Lei n ${ }^{\circ} 11.892$, de 29 de dezembro de 2008. Institui a Rede Federal de Educação Profissional, Científica e Tecnológica, cria os Institutos Federais de Educação, Ciência e Tecnologia, e dá outras providências. <http://www.planalto.gov.br/ccivil_03/_Ato2007-2010/2008/Lei/L11892.htm>.

Brasil. (2021). Lei n 12.677, de 25 de junho de 2012. Dispõe sobre a criação de cargos efetivos, cargos de direção e funções gratificadas no âmbito do Ministério da Educação, destinados às instituições federais de ensino e dá outras providências. <https://www2.camara.leg.br/legin/fed/lei/2012/lei-12677-25-junho-2012613458-normaatualizada-pl.html >.

Ciavatta, Maria; Ramos, Marise. (2001). Ensino Médio e Educação Profissional no Brasil. Dualidade e Fragmentação. Brasília: Revista Retratos da Escola. p36.

Colégio Pedro II. (2019). Planejamento Estratégico. Rio de Janeiro. <http://www.cp2.g12.br/usingjoomla/extensions/components/contentcomponent/articlecategories/9835-planejamento-estrat\%C3\%A9gico-2019-2013.html>. 
Research, Society and Development, v. 10, n. 3, e0210313192, 2021

(CC BY 4.0) | ISSN 2525-3409 | DOI: http://dx.doi.org/10.33448/rsd-v10i2.13192

Colégio Pedro II. (2019). Plano de Desenvolvimento Institucional. Rio de Janeiro.

<http://www.cp2.g12.br/images/comunicacao/2019/Outubro/pdi/1.\%20Plano\%20de\%20Desenvolvimento\%20Institucional.pdf>.

Di Pietro, Maria Sylvia Zanella. (2012). Direito Administrativo. São Paulo: Atlas.

Frigotto, Gaudêncio; Ciavatta, Maria; Ramos, Marise. (2005). Ensino médio integrado: concepção e contradições. São Paulo: Cortez.

G1. (2017). População que se declara preta cresce 14,9\% no Brasil em 4 anos, aponta IBGE. <https://g1.globo.com/economia/noticia/populacao-que-se-declarapreta-cresce-149-no-brasil-em-4-anos-aponta-ibge.ghtml.>.

Instituto Brasileiro de Geografia e Estatística (IBGE). (2021). PNAD Educaçao. <https://agenciadenoticias.ibge.gov.br/agencia-sala-de-imprensa/2013-agenciade-noticias/releases/28285-pnad-educacao-2019-mais-da-metade-das-pessoas-de-25-anos-ou-mais-nao-completaram-o-ensino-medio>.

Ministério da Educação (MEC). (2021). Relatório anual de análise dos indicadores de gestão das instituições federais de educação profissional, científica e tecnológica. Brasíla. < http://portal.mec.gov.br/docman/julho-2021-pdf/117321-caderno-de-indicadores-2019-tcu/file>.

Ministério da Educação (MEC). (2021). PNP. Plataforma Nilo Peçanha. Brasília. <http://plataformanilopecanha.mec.gov.br/2021.html>.

Meirelles, Hely Lopes. (2013). Direito administrativo brasileiro. 39. ed. São Paulo: Malheiros.

Pacheco, Eliezer. (2011). Os Institutos Federais - Uma revolução na educação profissional e tecnológica. São Paulo: Moderna,

Pacheco, Eliezer. (2015). “Apresentação e Fundamentos da Proposta Político Pedagógica” In:. Fundamentos Político-Pedagógicos dos Institutos Federais: diretrizes para uma educação profissional e tecnológica transformadora. Natal: IFRN. (PP. 6-27).

$<$ https://memoria.ifrn.edu.br/bitstream/handle/1044/1018/Fundamentos\%20PolíticoPedagógicos\%20dos\%20Institutos\%20Federais\%20-\%20Ebook.pdf?seque nce $=1 \&$ is Allowed $=\mathrm{y}>$

Pádua, E. M. M. (1997). Metodologia da pesquisa: abordagem teórico-prática. 2. ed. São Paulo: Papirus.

Pereira A.S. et al. (2018). Metodologia da pesquisa científica. [e-book]. Santa Maria. Ed. UAB/NTE/UFSM. https://repositorio.ufsm.br/bitstream/handle/1/15824/Lic_Computacao_Metodologia-Pesquisa-Cientifica.pdf?sequence=1.

Ramos, Marise. (2005). Possibilidades e desafios na organização do currículo integrado. In: Frigotto, Gaudêncio; Ciavatta, Maria; Ramos, Marise. Ensino Médio Integrado: concepções e contradições. São Paulo: Cortez. 